\title{
Limit Analysis approach for the in-plane collapse of masonry arches
}

M. Pepe PhD, CEng

Post Doc, Department of Structural and Geotechnical Engineering, Sapienza University of Rome, Rome, IT (Orcid: 0000-0002-9416-8415) M. Pingaro PhD, CEng

Post Doc, Department of Structural and Geotechnical Engineering,

Sapienza University of Rome, Rome, IT (Orcid: 0000-0002-7037-8661)

P. Trovalusci PhD
Full Professor of Solids and Structural Mechanics, Department of Structural and Geotechnical Engineering, Sapienza University of Rome, Rome, IT (corresponding author: patrizia.trovalusci@uniroma1.it) (Orcid: 0000-0001-7946-3590)

The present paper deals with the numerical evaluation of the in-plane collapse behaviour of unreinforced masonry arches and portals characterized by different geometries subjected to several loading conditions and modelled as assemblages of rigid blocks in contact through no-tensional and frictional interfaces. This study has been conducted using a new in-house code, which represents the updated version of the numerical procedure presented in the pioneering work of Baggio and Trovalusci (2000). The minimization problem corresponding to the Upper Bound (or kinematic) approach of Limit Analysis is written as a Linear Programming Problem solved taking advantages of the algorithms nowadays available. An important feature of the code is the capability to provide information about the sliding collapse of masonry structures, adopting the assumption of dilatancy in the analytic description of the yielding surface, permitting to overcome the classical Heyman's hypothesis which limited the investigation of collapse to only hinging modes.

A key contribution of the work is the comparison of results in terms of collapse multipliers and collapse mechanisms considering different literature contributes as benchmark references. The presented study reveals the suitability of approaches based on mathematical programming and the crucial role played by sliding.

\section{Introduction}

Historical masonry structures play a central role in the world's building heritage and especially in the Italian territory where a large number of buildings are of historical interest. Generally these buildings are characterized by the presence of portions composed of arches and vaults that, as well known in literature, have little resistance to horizontal actions such as the seismic ones and the problem of their seismic vulnerability is a very critical issue. For these reasons, the study of masonry structures and in particular historical ones is currently open to scientific debate for the development of suitable methodologies to correctly simulate the response of these structures, including realistic constitutive assumptions and considering the problem of the strong non-linear response of masonry. Thanks to the great increase of computational capacity in recent decades, a large number of numerical applications have been developed, enriching the literature of methods for the study of historical masonry.

Focusing on brick/block masonry, the different approaches include: micromechanical models (Lotfi and Shing, 1994; Lourenço and Rots, 1997; Oliveira and Lourenço, 2004; Alfano and Sacco, 2006), where the constituents, that is units and interfaces, made of mortar if present, between elements are separately modelled and to each part is assigned a properly calibrated constitutive law;

- macromechanical models (Del Piero, 1989; Gambarotta and Lagomarsino, 1997; Roca et al., 2005), in which the heterogeneous medium is modelled as a continuum and the constitutive behaviour is usually described through phenomenologically based mathematical relations, also including degrading phenomena described through damage or friction variables;

multiscale, continuum models derived from finer descriptions, in such case micro-macro models, which represent a very promising approach for the analysis of masonry structures since they can accurately keep track of the the mechanical and geometrical properties of the material at the microstructure scale with a reduced computational cost if compared to a fully micromechanical model (Masiani and Trovalusci, 1996; Trovalusci et al., 2010; Leonetti et al., 2018; Reccia et al., 2018). They are generally based on the classical homogenization 
strategies, based on the solution of boundary element problems at the micro-level, (Addessi et al., 2018, 2016; Greco et al., 2016,2017 ) or on other coarse-graining strategies, based on the so-called Cauchy rule and its generalizations (Trovalusci, 2014; Capecchi et al., 2011), also allowing the derivation of generalized continua such as micropolar continua able to properly account for scale effects, that in masonry materials are significant (Masiani and Trovalusci, 1996; Trovalusci and Masiani, 2003; Trovalusci and Pau, 2014; Fantuzzi et al., 2019; Leonetti et al., 2019).

Nowadays technicians and engineers can rely on different tools for their structural analysis which could be based on non-linear or linear approaches. While the former requires great knowledge about the solution techniques, a good characterization of material properties and often a great computational effort to approach the numerical problem, the latter could be considered a more practical tool even if not able to capture the behaviour of material over the elastic limit, i.e. considering the cracking and damaging phenomena.

In this context, the application of Limit Analysis to assess the safety of a masonry structure, although not able to provide information about its deformability, permits the evaluation of its ultimate load capacity and the corresponding failure mechanism, requiring a limited number of material input parameters, overcoming the common difficulties of obtaining reliable experimental data for historical masonry structures. As well known, Kooharian (Kooharian, 1952) and Heyman (Heyman, 1966, 1969, 2017) were the first to consider masonry structures in the context of the plastic Limit Analysis theory, bringing the problem back to a preelasticist approach, i.e. considering the verification of the masonry structure as a geometric problem of equilibrium rather than a stress calculation analysis. The structure is discretised into several rigid bodies, which could be the effective single blocks composing the structure or parts of the structure, which behave as macro rigid blocks, interacting through contact surfaces. In particular, Heyman (1966, 1969) discussed the basic hypothesis upon which Limit Analysis would be applicable to masonry structures and which are still today the basis of many Limit Analysis models: (a) sliding cannot occur, (b) masonry has no tensile strength, (c) masonry has an infinite compressive strength and (d) failure occurs under small displacements. Notwithstanding the great importance of the author's contribution and its implications to the collapse analysis, in many real cases it could be limitative to exclude from the analysis the presence of finite resistance to friction, as this reduces the evaluation of the collapse of a masonry structure only to the occurrence of hinging mechanisms.

The first known pioneering contribute concerning the possibility to consider in the study of the collapse of masonry structures the presence of friction is due to Coulomb. "Essai sur une application des regles de maximis et minimis a quelques problemes de statique relatifs a l'architecture" (Coulomb, 1776) was published in a collection of mathematical and physical memoirs by the Académie Royal des Sciences in 1776. Coulomb begins his specific treatment of vaults taking as subject the barrel vault, asserting that the same principles can be applied to any other type of vault (See a report in (Benvenuto, 1991)).

After providing three corollary regarding the equilibrium of the vaults, the author presents a radical change respect to the ideas which, till then, had governed the science of masonry constructions. Indeed, while other authors tried to adapt the dimensions of a vault so that its stresses should conform to a given static scheme (verification), Coulomb proposed an opposite approach determining what stress could arise given a vault of defined shape and dimensions (design).

As shown in Figure 1, Coulomb considers the critical joint (identified by the angle $\phi$ ) that can be activated in a generic position, unlike other authors which, arbitrarily, identified the fracture inclined at a given angle. Figure 2 shows the four limit cases immediately before collapse considered by the author, including sliding (a)-(b) and hinging (c)-(d) mechanisms. From

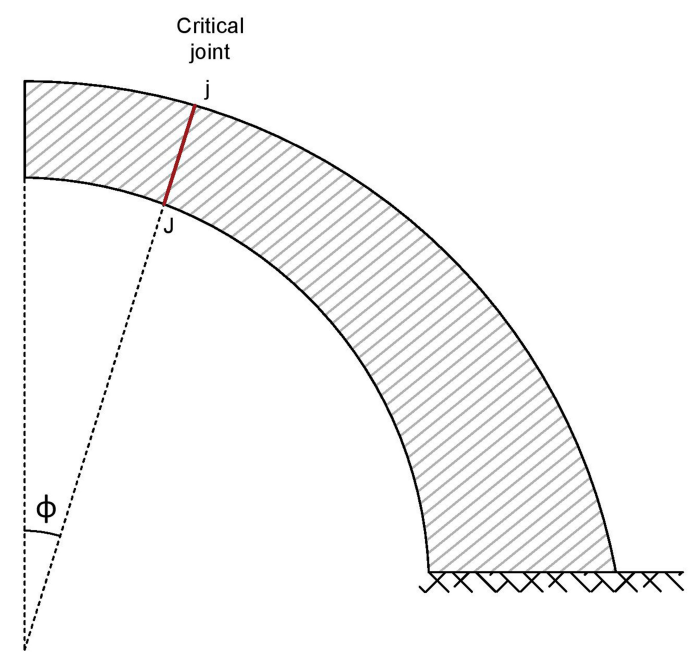

Figure 1. Benvenuto (1991), the geometry of the vault of finite size at incipient collapse according to Coulomb

the mathematical point of view Coulomb identifies two different inequalities, one for hinging and one for sliding collapse, describing the limit equilibrium of the vault as a function of the horizontal and vertical loads, including also friction. Coulomb recognises that in the presence of sliding mechanisms the solution is not unique. The position the critical joints is then obtained following a solved with a trial and error strategy by varying its position. 


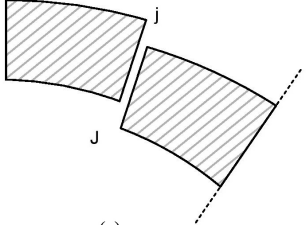

(a)

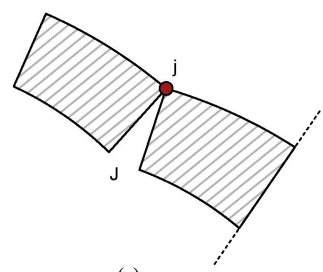

(c)

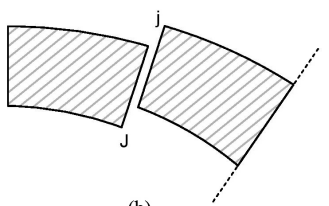

(b)

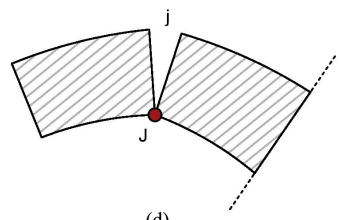

(d)
Figure 2. Benvenuto (1991), sliding (a)-(b) and hinging collapse (c)-(d) according to Coulomb

In the last decades, among masonry structures, many authors have been focused the attention in particular on the study of masonry arches (Boothby, 1994; Barsotti et al., 2017; Aita et al., 2020; Eroglu et al., 2020) adopting different approaches such as dynamic approach (Oppenheim, 1992; De Lorenzis et al., 2007a,b; Peña et al., 2007); Isogeometric approach (Chiozzi et al., 2016); Discrete Element Method (DEM) (Baraldi et al., 2019); homogenization technique (Reccia et al., 2013) or multiscale approach (Di Re et al., 2018). A recent work of Bruggi (2020) adopt the optimization process for study the optimal shape for arches and vaults.

This work focus the attention on the study of the ultimate behaviour of masonry arches of different geometries and shape, considering the presence of friction, considered by several authors (Ferris and Tin-Loi, 2001; Mousavian and Casapulla, 2020; Portioli et al., 2014; Casapulla and Maione, 2020), and comparing results with several contributes present in literature (Brandonisio et al., 2017; Calderini and Lagomarsino, 2015; Como, 2015; Misseri et al., 2018; DeJong et al., 2008). In particular, starting from (Baggio and Trovalusci, 2000), a new version of the ALMA code (Analisi Limite Murature Attritive) has been developed based on the Limit Analysis (Pepe, 2020; Pepe et al., 2019, 2020a) namely ALMA 2.0. ALMA 2.0 has been implemented in recent coding language of Python ${ }^{T M}$ permits an easy and fast scalability and improving of the code. The easy linking of external packages permits to adopt the advantages of the lasted optimization subroutine, in particular, in this work MOSEK library (www.mosek.com) has been adopted for solving the optimization problem. Other important issues regard the input file in which the main input is a simple DXF file of the structure and the post-process results, that are plotted in ParaView (more details in (Pepe, 2020)). Furthermore, the new version of the code
(Pepe et al., 2019, 2020a) overcome the limit in term of number of blocks respect to the original version (Baggio and Trovalusci, 2000) and it has been improved in order to take into account foundation settlement (Pepe et al., 2020b), cohesion between the joints and retrofitting cable (Pepe, 2020).

Computational limit analysis, as adopted here, is largely recognized as a very effective tool to estimate collapse load and collapse mechanisms for masonry structures (Baggio and Trovalusci, 1998, 2000; Milani, 2011; Milani and Taliercio, 2016; Rossi et al., 2020; Cascini et al., 2020; Grillanda et al., 2019) or masonry structures in presence of settlements (Landolfo et al., 2020; Pepe et al., 2020b). The code is used to determine the failure configuration of dry joints masonry arches, modelling the arches (according to a microscale approach) as an assemblage of rigid blocks in contact through frictional and no-tension interfaces.

In order to cope the non linear problem different strategies have been developed. One of these is based on the possibility to individuate, for a given distribution of loads, a certain number of joints through which negligible interactions are transmitted. Then the problem can be reduced to a weakly non linear optimization problem. The other method, here adopted, consists of linearising the problem assuming an associated collapse mechanism of sliding; i.e., considering, as indicated by Drucker (1953), joints with dilatancy.

Therefore, although the theorems of limit analysis adapted to assemblages of bodies with frictional interfaces (Drucker, 1953) state that the limit load obtained with the linear program is an upper bound of the collapse load, to obtain results near to the actual ones, the burden of non linear programming can sometimes be avoided by replacing friction with dilatancy. Different assumptions on the amount of dilatancy, i.e. zero or negative, can be found in Gilbert et al. (2006), but in these cases the normality rule is satisfied by modifying the yield surface.

The paper has been organized as follow: in Section 2 we recall the governing equations of the non-standard limit analysis problem, in Section 3 the numerical results obtained for different cases of arches have been presented and in Section 4 some final remarks are highlighted and future developments are reported.

\section{Limit Analysis model}

In this work the notation used in Baggio and Trovalusci (1998, 2000 ) is adopted, in which masonry structures can be described as a system of $n$ rigid blocks and $m$ joints unable to carry tension and resistant to sliding by friction. The blocks can translate and rotate about the edges of the contact blocks (hinging) as well as slide along the joints. A in-plane case of Limit Analysis has been considered, as shown in Figure 3 in which two blocks are depicted. 
Let consider the orthonormal basis in the two-dimensional space $\boldsymbol{e}=\left\{e_{1}, e_{2}\right\}^{T}$. The loads, applied in the respective centroid of mass of each $i^{\text {th }}$ rigid block, are collected in two vectors of generalized loads $\boldsymbol{f}_{0}^{i}=\left\{f_{01}^{i}, f_{02}^{i}, m_{0}^{i}\right\}^{T}$ and $\boldsymbol{f}_{L}^{i}=$ $\left\{f_{L 1}^{i}, f_{L 2}^{i}, m_{L}^{i}\right\}^{T}$, which represent constant ('dead') and variable ('live') loads, respectively. The subscripts $L$ and 0 have been adopted for the live and dead load, respectively. In both cases the vector $f_{\star}^{i}$, with $i=1,2, \ldots, n$, contains the two components of the force and the moment applied to $i^{\text {th }}$ block.

Considering all blocks component the structure, for the sake of brevity, we assume the global load vectors $\boldsymbol{f}_{0}=\left\{\boldsymbol{f}_{0}^{i}\right\}$ and $\boldsymbol{f}_{L}=$ $\left\{\boldsymbol{f}_{L}^{i}\right\}$, with $i=1, \ldots, n$. As usual in the Limit Analysis the load vector is split in two parts as follow

$$
\boldsymbol{f}=\underbrace{\boldsymbol{f}_{0}}_{\text {Dead Load }}+\underbrace{\alpha \boldsymbol{f}_{L}}_{\text {Live Load }},
$$

where live loads are proportional to the dead loads through a nonnegative coefficient $\alpha$, called load multiplier.

Let $\boldsymbol{u}^{i}=\left\{u_{1}^{i}, u_{2}^{i}, \theta^{i}\right\}^{T}$ denote the vector of generalized displacement of the centroid of each $i^{\text {th }}$ block, that contains the displacement components $u_{1}, u_{2}$, and the rotation $\theta$. As previously, we define the collection of all single vector of generalized displacement in a global vector $\boldsymbol{u}\left\{\boldsymbol{u}^{i}\right\}$, with $i=1, \ldots, n$, which corresponds in the virtual work sense to the global load vector $f$.

The static variables are the internal forces acting at each $j^{\text {th }}$ contact surface between blocks, with $j=1, \ldots, m$. Whose components are the normal force $N^{j}$, the shear force $T^{j}$ and the moment $M^{j}$. For each joint they are collected in the vector of generalized stress $\boldsymbol{\sigma}^{j}=\left\{N^{j}, T^{j}, M^{j}\right\}^{T}, j=1, \ldots, m$, referred to the whole structure.

The kinematic variables, or generalized strain, are the relative displacement rates at joints, that is normal displacement $\xi^{i}$, tangential displacement $\gamma^{i}$ and rotation $\chi^{i}$. For each joint $j=$ $1, \ldots, m$ they are collected in the vector $\epsilon=\left\{\xi^{i}, \gamma^{i}, \chi^{i}\right\}^{T}$. The vector $\boldsymbol{\epsilon}=\left\{\boldsymbol{\epsilon}^{i}\right\}$ refers to the whole structure and corresponds in a virtual work sense to the vector of static variables $\sigma$.

The kinematic compatibility for the whole system is expressed by equation

(2) $\boldsymbol{\epsilon}=\boldsymbol{B} \boldsymbol{u}$,

where $\mathbf{B}$ represents the compatibility matrix defined in (Baggio and Trovalusci, 2000).

The equilibrium of the whole structure is defined by the equation

(3) $\boldsymbol{B}^{T} \boldsymbol{\sigma}+\boldsymbol{f}=\mathbf{0}$.

The generalized yield domain of the system can be written as

(4) $\boldsymbol{y}=\boldsymbol{N}^{T} \boldsymbol{\sigma} \leq \mathbf{0}$,

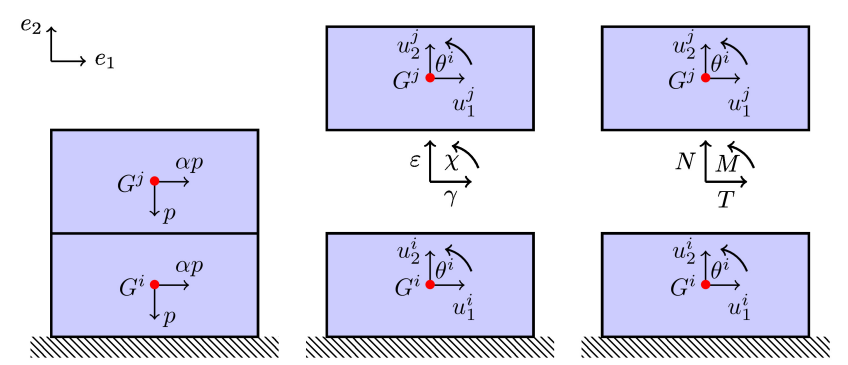

Figure 3. Schematic representation of a two-block structure with one joint: dead and live loads (left), kinematic (center) and static variables (right)

where $N$ is the block-diagonal gradient matrix referred to the adopted failure surface.

The non-associative flow rule expresses the vector $\epsilon$ as a linear combination of non-negative coefficients ordered in the vector $\boldsymbol{\lambda}$, called inelastic multiplier, and it can be written as

$$
\text { (5) } \epsilon=M \lambda \text {. }
$$

Finally, the following complementarity condition must be satisfied

(6) $\boldsymbol{\lambda}^{T} \boldsymbol{y}=0$.

Furthermore, the non-negative work of the live loads which cause the collapse mechanism is defined by the following equation

$$
\text { (7) } \boldsymbol{f}_{L}^{T} \boldsymbol{u}=1
$$

Within the framework of the holonomic perfect plasticity, the same relations govern the problem of a non-standard rigid-plastic discrete material. Resorting this formal analogy, the collapse load for a masonry structure, under the hypothesis of proportional load with the factor $\alpha>0$, can be determined. After some algebra the following non-linear and non-convex programming problem (NLNCP) is obtained

$$
\begin{aligned}
\alpha_{C}= & \min \{\alpha\} \text { subjected to } \\
& \left(\boldsymbol{A} \boldsymbol{M}_{1}-\boldsymbol{M}_{2}\right) \boldsymbol{\lambda}=0, \\
& \left(\boldsymbol{A}_{0} \boldsymbol{N}_{1}^{T}\right)\left(\boldsymbol{f}_{0}+\alpha \boldsymbol{f}_{L}\right)+\left[\boldsymbol{N}_{2}^{T}-\left(\boldsymbol{A} \boldsymbol{N}_{1}\right)^{T}\right] \boldsymbol{\sigma}_{2} \leq 0, \\
& \boldsymbol{\lambda}^{T}\left(\boldsymbol{A}_{0} \boldsymbol{M}_{1}\right)^{T} \boldsymbol{f}_{L}-1=0, \\
& \boldsymbol{\lambda}^{T}\left\{\left(\boldsymbol{f}_{0}+\alpha \boldsymbol{f}_{L}\right)+\left[\boldsymbol{N}_{2}^{T}-\left(\boldsymbol{A} \boldsymbol{N}_{1}\right)^{T}\right] \boldsymbol{\sigma}_{2}\right\}=0,
\end{aligned}
$$

where $\alpha_{C}$ is the collapse multiplier and where introducing $\boldsymbol{B}_{1}$, that is the kinematical submatrix of maximum rank and $\boldsymbol{B}_{2}$ the rest of the kinematical matrix, the matrix $\boldsymbol{A}_{0}$ is the inverse of $\boldsymbol{B}_{1}$. The matrix $\boldsymbol{A}$ is defined as $\boldsymbol{A}=\boldsymbol{B}_{2} \boldsymbol{B}_{1}^{-1}$ and $\boldsymbol{N}$ is the transpose of the block-diagonal gradient matrix $\left(N=\left[N_{1} ; N_{2}\right]\right)$. 
The unknowns of the problems are: $\alpha, \boldsymbol{\sigma}_{2}, \boldsymbol{\lambda}$ with the bounds $\boldsymbol{\lambda} \geq \mathbf{0} ; \boldsymbol{\sigma}_{2}$ are the undetermined unknown of the system which represent the statically undetermined term of the generalized stress $\boldsymbol{\sigma}$ (Baggio and Trovalusci, 1998).

For systems with non-associated flow rules the Drucker stability postulate no longer holds, the solution loses its uniqueness and lower/upper bounds for the collapse multipliers can be found (Drucker, 1953; Radenkovic, 1961). The solution of a non-linear and non-convex programming problem could not exist and when it is found, it can be locked in a local minimum rather than the global one (Kirsch, 1993).

In order to deal with the NLNCP, authors (Baggio and Trovalusci, 2000) developed a specific computational code (ALMA: Analisi Limite Murature Attritive), based on a two-step procedure: initially a linear programming problem (LP), obtained by assuming dilatancy instead of friction, hypothesis which makes the problem governed by associative flow rule, is solved, followed by the attempt to approach the non-linear solution using as initial guess of NLNCP the solution previously obtained for such LP.

As the solutions obtained following the approach of replacing friction with dilatancy LP (first step), which in most cases provided results frequently quite close to the solutions of NLCP (second step), both in terms of collapse multipliers and mechanisms Baggio and Trovalusci (2000), in this work we decided to focus on the linear programming optimization problem (firstly developed in the seminal paper by Livesley (1978)), referred as the upper bound approach of Limit Analysis, for providing collapse multipliers and the corresponding collapse mechanisms of analysed structures. It is known that when normality rule holds the static and kinematic theorems of Limit Analysis can be considered as two dual problems of linear programming optimization, which lead to a unique solution. In particular, the adopted kinematic upper bound problem is defined as

$$
\begin{aligned}
\alpha_{C}= & \min \left\{-\boldsymbol{\lambda}^{T}\left(\boldsymbol{A}_{0} \boldsymbol{N}_{1}\right)^{T} \boldsymbol{f}_{0}\right\} \text { subjected to } \\
& \left(\boldsymbol{A} \boldsymbol{N}_{1}-\boldsymbol{N}_{2}\right) \boldsymbol{\lambda}=\mathbf{0}, \\
& \boldsymbol{\lambda}^{T}\left(\boldsymbol{A}_{0} \boldsymbol{N}_{1}\right)^{T} \boldsymbol{f}_{L}-1=0,
\end{aligned}
$$

with the bounds on the unknowns $\boldsymbol{\lambda} \geq \mathbf{0}$.

\section{Numerical Results}

This section regards the numerical results obtained using ALMA 2.0 and their comparison with a corresponding benchmark test. First the arch experimented and studied by Cancelliere et al. (2010) is presented. In the following a comparison of experimental and numerical results with those available in the literature Brandonisio et al. (2017) and Misseri et al. (2018) is reported.

\subsection{The arch analysed by Cancelliere et al.}

The first $b$ enchmark $t$ est $c$ onsidered i s t he $s$ emi-circular arch analysed by Cancelliere et al. (2010). The paper presents an experimental campaign and the corresponding numerical modelling of unreinforced and reinforced masonry arches, the latter strengthened with fiber reinforced plastic (FRP) strips. Authors proposed a non-linear elastic constitutive law for the masonry material, developing a specific beam finite element and implementing a numerical procedure, based on the Newton-Raphson method, to solve the non-linear structural problem. In order to identify the maximum load capacity and the corresponding collapse mechanism of the arch, an experimental collapse test has been performed applying an external eccentric load to the structure. Figure 4 presents the experimental test on the unreinforced arch which collapse in correspondence of an ultimate load of about $500 \mathrm{~N}$ exhibiting four alternated plastic hinges, two at the extrados and two at the intrados. In particular the formation of the hinges is due to the decohesion of the mortar/brick interface. Figure 5 shows the unreinforced arch reproduced in ALMA 2.0,

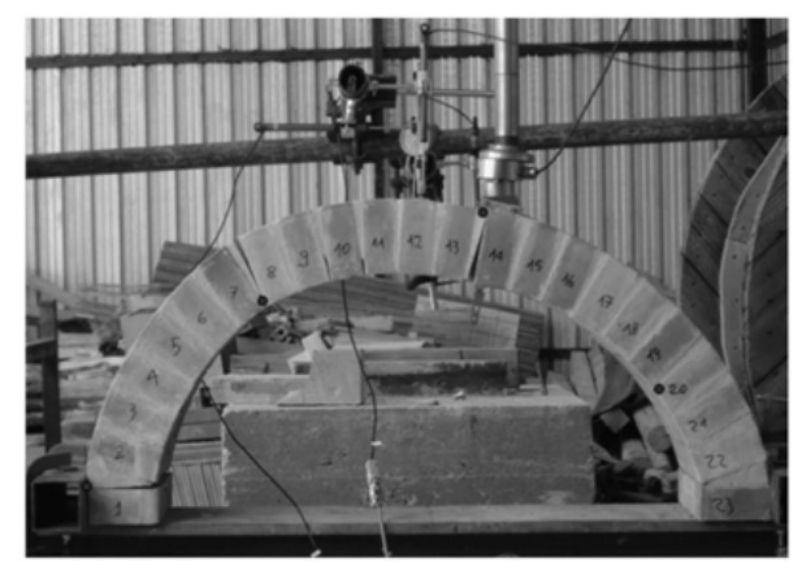

Figure 4. Experimental sample on unreinforced masonry arch taken from Cancelliere et al. (2010)

where the real voussoir are modelled as trapezoidal blocks in mutual contact with extended lateral dimension, in order to include the thickness of real mortar layer not explicitly considered in the code. Figure 6 presents the collapse mechanism obtained with the LA code. The result is in perfect agreement with the experimental test and numerical results obtained by authors, providing the same number and position of plastic hinge in correspondence of a collapse load of about $470 \mathrm{~N}$. The only difference is related to first and last blocks of the arch, free to rotate in the LA code while fixed in experimental test. This detail affected the position of the hinges placed between ground and block $\mathrm{n}^{\circ} 1$ and hinges placed between blocks $n^{\circ} 7$ and $n^{\circ} 8$, which result shifted by one block if compared to the experimental test.

\subsection{The arch analysed by Brandonisio et al.}

Authors proposed a Limit Analysis approach combined with a non-linear programming technique to evaluate the seismic capacity of masonry circular arches supported on buttresses, subjected to 


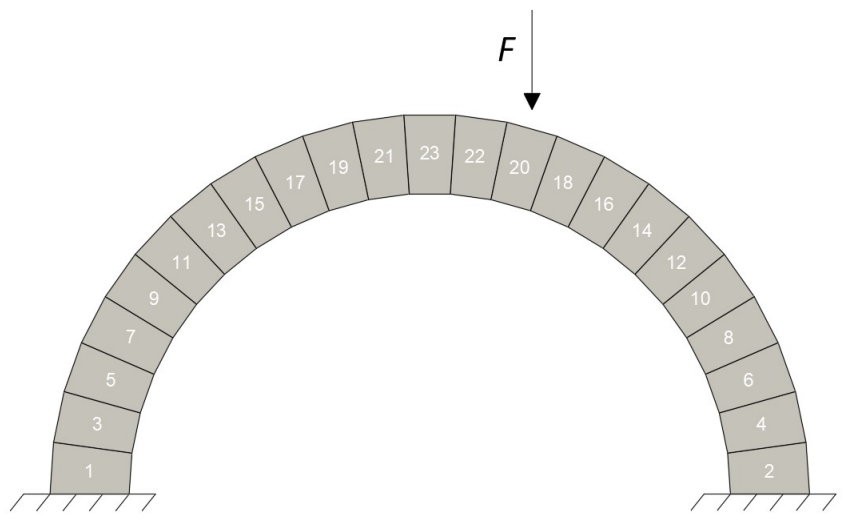

Figure 5. Cancelliere et al. (2010) arch, representation of the arch in ALMA 2.0

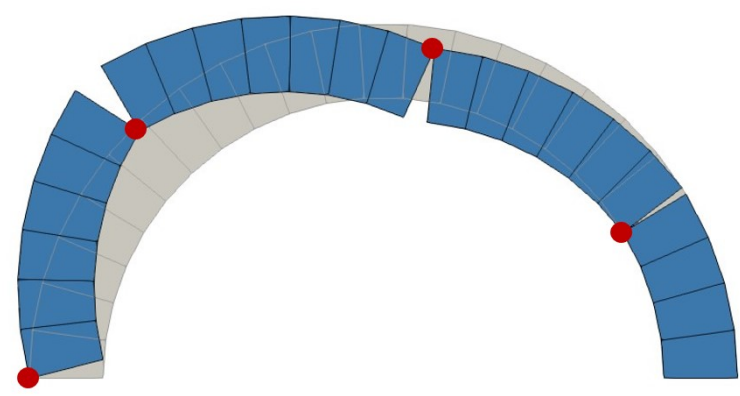

Figure 6. Cancelliere et al. (2010) arch, collapse mechanism obtained with ALMA 2.0

live horizontal forces in terms of collapse multipliers and failure mechanism (Brandonisio et al., 2017). In particular the formation of three distinct failure mechanisms is taken into account: arch mechanism in Figure 7(a), global mechanism in Figure 7(b) and mixed mechanism Figure 7(c). The analytic formulation of the problem is characterized by objective function and constraints conditions which are smooth non-linear functions of the decision variables. Authors proposed an automatic procedure based on a non-linear programming technique to minimize the unknown collapse multiplier by varying the hinge locations $\theta_{A}, \theta_{B}, \theta_{C}$ and $\theta_{D}$. In order to validate their numerical procedure, a comparison with experimental and numerical literature results of four different arched structures, studied by DeJong et al. (2008), Como (2015), Calderini and Lagomarsino (2015) and Dimitri and Tornabene (2015), is provided.

DeJong et al. (2008) tested an arch made of 15 autoclave aerated concrete geometrically characterized by span length $L=0.36 \mathrm{~m}$, internal radius $R=0.185 \mathrm{~m}$, thickness $t=0.03 \mathrm{~m}$, transversal width $s=0.10 \mathrm{~m}$ and springer at $\beta=14^{\circ}$ (see Figure 8(a)).

Como (2015) analysed an arch made of tuff block and mortar masonry geometrically characterized by span length $L=15 \mathrm{~m}$, internal radius $R=7.5 \mathrm{~m}$, thickness $t=1.20 \mathrm{~m}$, and transversal width $s=4 m$ (see Figure 8(b)). The iterative procedure proposed by Como (2015) allows for calculating the smallest kinematic multiplier by varying the position of the hinges $\mathrm{B}$ and $\mathrm{C}$ in the arch, being the hinges $\mathrm{A}$ and $\mathrm{D}$ fixed.

Calderini and Lagomarsino (2015) carried out an experimental program to investigate the structural response under seismic action of a scaled buttressed arch, with and without the use of a reinforcing tie-rod. The examined specimen was composed of discrete blocks made of plastic material and it is characterized by the following geometrical dimensions: span length $L=0.46 \mathrm{~m}$, internal radius $R=0.22 \mathrm{~m}$, thickness $t=0.075 \mathrm{~m}$, angle of embrace 170, pier height $h=0.55 m$, pier width $B=0.13 m$ (see Figure 9).

Dimitri and Tornabene (2015) provide a parametric investigation on the seismic capacity of arches and buttressed arches of different shapes by means of Discrete Element Method. The geometry of the examined structure is characterized by $L=2 \mathrm{~m}, R=1 \mathrm{~m}$, $t=0.22 \mathrm{~m}$, angle of embrace $180, h=3.33 \mathrm{~m}, B=0.89 \mathrm{~m}$ (see Figure 9).

The same structures used as benchmark by Brandonisio et al. (2017) have been modelled using the Limit Analysis LP code ALMA 2.0. The potentiality of the code to deal with large number of degrees of freedom has been a crucial point, permitting to compare the position of the hinges at collapse. Indeed, as shown in Figure 10, the analysed arches have been subdivided into rigid blocks positioned every $1^{\circ}$ with respect to the arch center. Figure 11 presents the results obtained by the several authors in terms of collapse multipliers compared with those of ALMA 2.0. In particular:

DeJong: the collapse multiplier obtained with ALMA 2.0 coincides with the result provided by authors.

- Como: the collapse multiplier obtained with ALMA 2.0 results very little lower respect the value obtained by the authors. The value obtained by Brandonisio et al. (2017) results on the contrary just a little higher.

Lagomarsino: referring to the unreinforced structure, the collapse multiplier obtained with ALMA 2.0, as well as the value obtained by Brandonisio et al. (2017), results little lower respect the value obtained by authors.

Dimitri: the collapse multiplier obtained with ALMA 2.0 as well as the value obtained by Brandonisio et al. (2017) result very close to the value obtained by authors, even if little higher. 


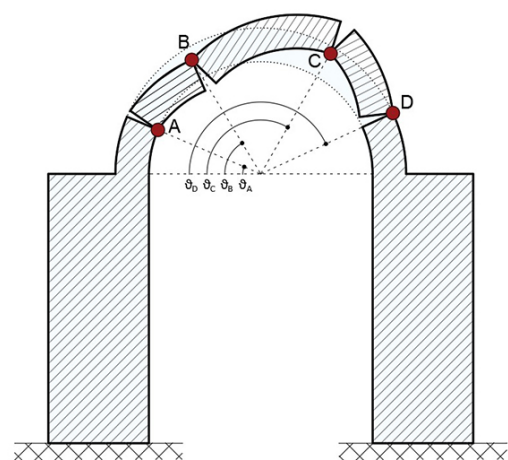

(a)

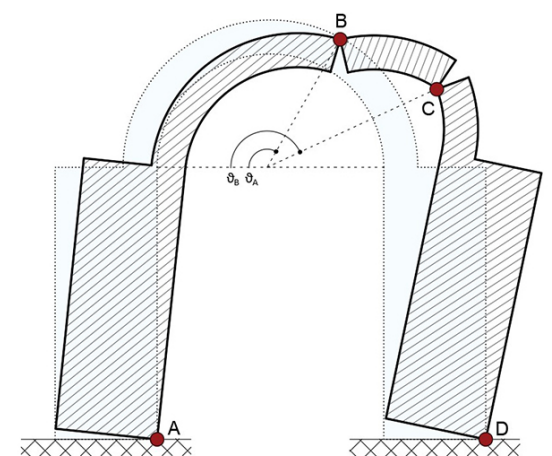

(b)

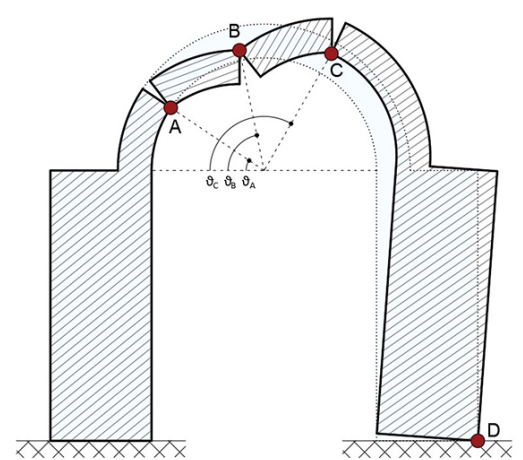

(c)

Figure 7. Brandonisio et al. (2017): the three typologies of collapse mechanisms considered

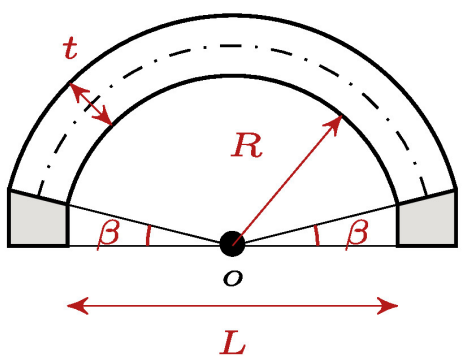

(a)

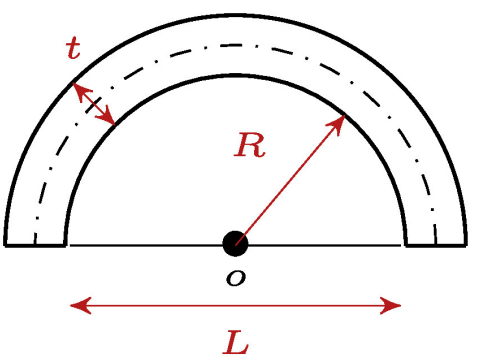

(b)

Figure 8. Geometries considered by DeJong et al. (2008) (a) and Como (2015) (b)

Figures 12, 13 and 14 show the collapse mechanisms obtained with ALMA 2.0 referring to the arch studied by DeJong, Como, Calderini and Dimitri, respectively. At this regard, Figures 15, 16, 17 and 18 present a comparison of the position of the collapse hinges for each examined arch. It is possible to notice how the mechanisms differ,

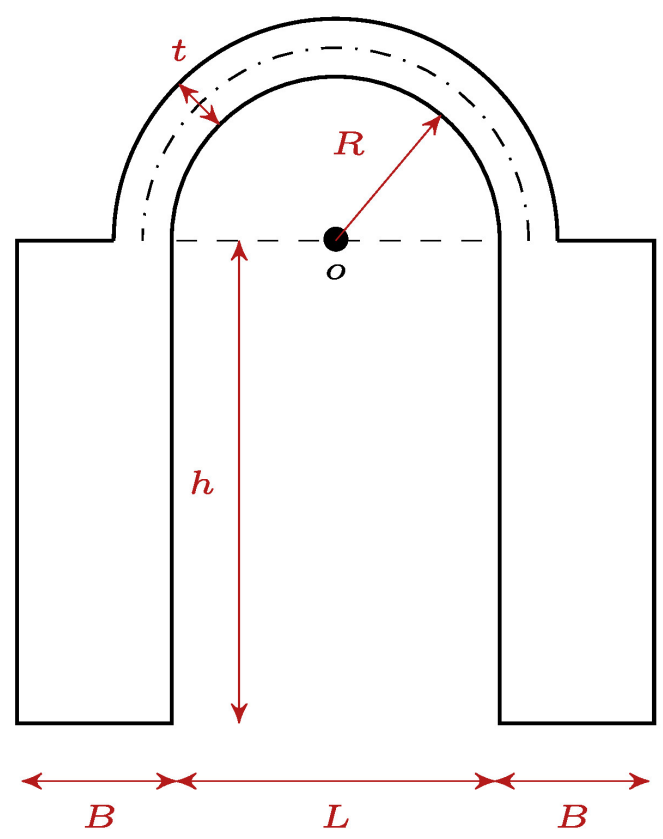

Figure 9. Geometry considered by Calderini and Lagomarsino (2015) and Dimitri and Tornabene (2015)

respect to results obtained by the several authors, negligibly with discrepancy in some case of just some degrees.

\subsection{The arch analysed by Misseri et al.}

An important contribute regarding the different collapse modalities that can occur for an arch, i.e. hinghing or sliding mechanism, is given from the work of Misseri et al. (2018). Authors studied the response of pointed arches under equivalent static (horizontal) loads pointing out the main differences between the results of 


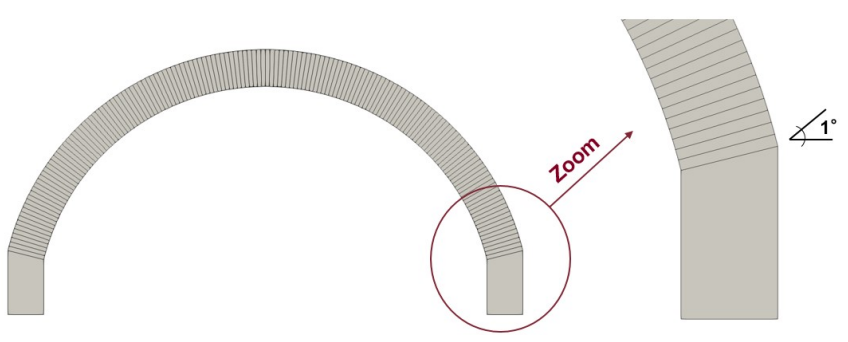

Figure 10. Detail of modelling adopted with ALMA 2.0

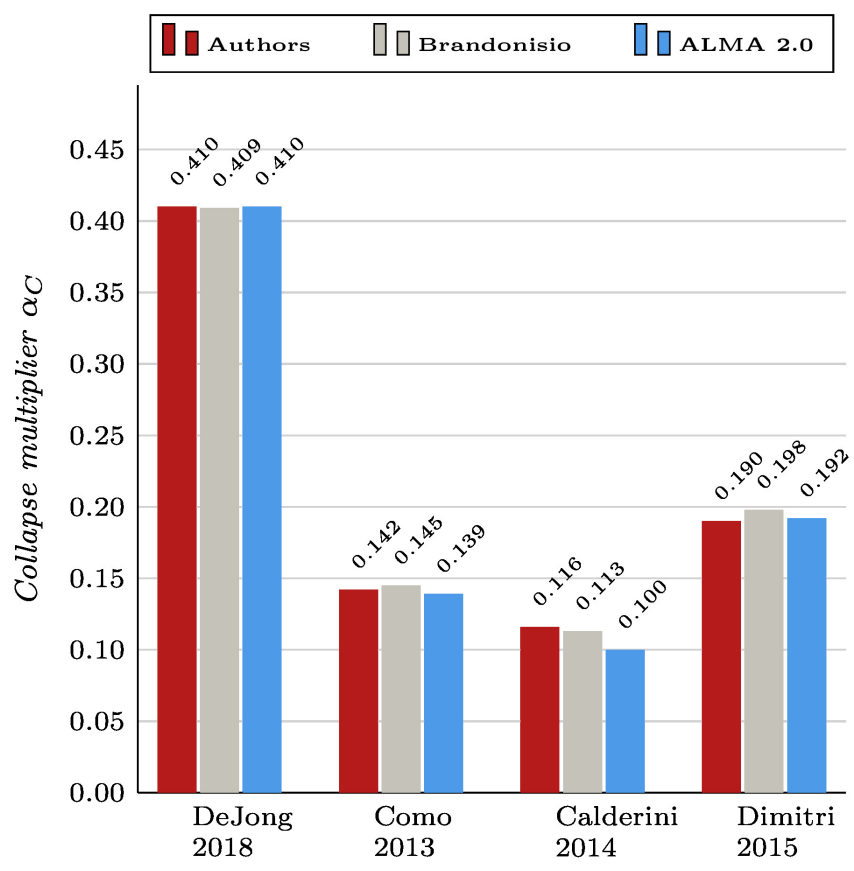

Figure 11. Comparison of collapse multipliers $\alpha_{C}$

the analytical model proposed, based on a Limit Analysis with kinematic approach, and the outcomes of an extensive experimental campaign considering eleven models reproduced in scale $(1: 10$ ratio) shown in Figure 19. This typology of experimental set-up is very intuitive and relatively simple to perform, permitting to verify how a scaled dry block structure collapses. It had already been successfully introduced at the Department of Structural and Geotechnical Engineering, as reported in Baggio and Trovalusci (1993) to study the ultimate behaviour of scaled dry masonry panels of different geometries and textures.

As shown in Figure 20 models were shaped starting from two arcs of a circumference with centres, points $c_{1}$ and $c_{2}$, placed symmetrically respect to the axis of symmetry $\left(\boldsymbol{e}_{2}\right)$. All arches have a fixed span $s=2 R_{c}$, where $R_{c}=400 \mathrm{~mm}$ is the radius of a

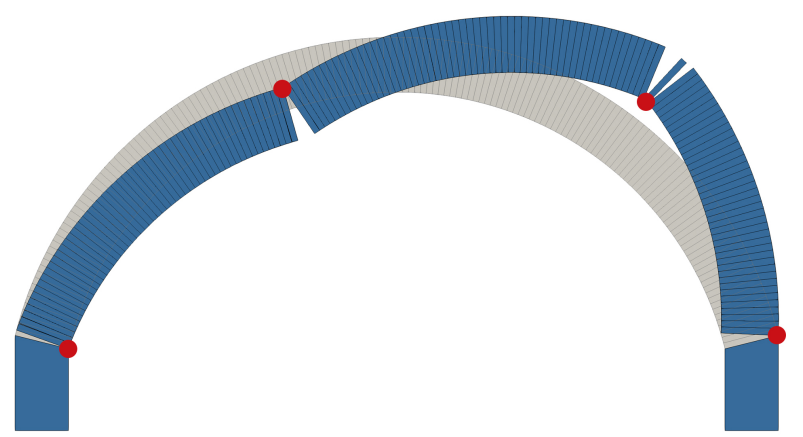

Figure 12. ALMA 2.0: the collapse mechanism obtained with the code referring to the arch studied by DeJong et al. (2008)

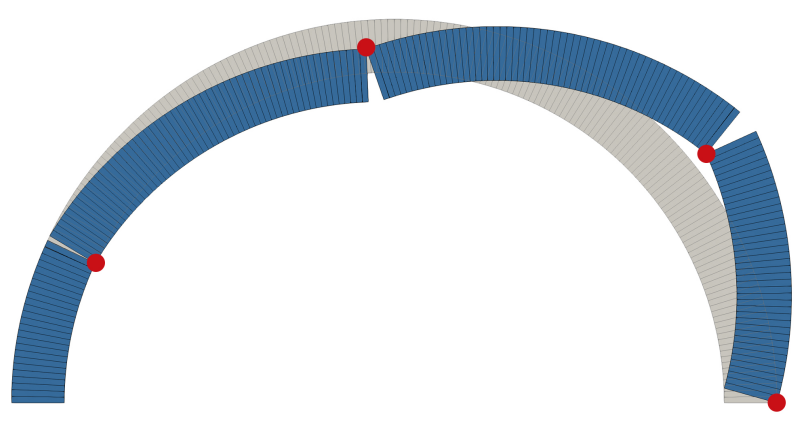

Figure 13. ALMA 2.0: the collapse mechanism obtained with the code referring to the arch studied by Como (2015)

circular arch with the same span $s$, and varying rise and thickness $t$. The eccentricity $e$ is defined as the distance between the symmetry axis $e_{2}$ and the centre of the circumference $o$ and it has been varied to create three classes of sharpness, $S h=e / R_{c}$. Thickness, $t$, was ranged into four classes of slenderness, $S d=t / R_{p}$, where $R_{p}=e+R_{c}$ is the radius of the pointed arch evaluated on the mid-line. The values of $S h$ are fixed to $0.2,0.6,1$ and values assigned to $S d$ are $0.1,0.15,0.2,0.25$ (the specimen with $S h=0.2$ and $S d=0.1$ was not considered). In particular, the models have been built in autoclaved aerated concrete and composed by 17 blocks, including 16 voussoirs and the crown block, by varying their rise and thickness. Figure 19 shows the complete set of arches considered in the analysis. 


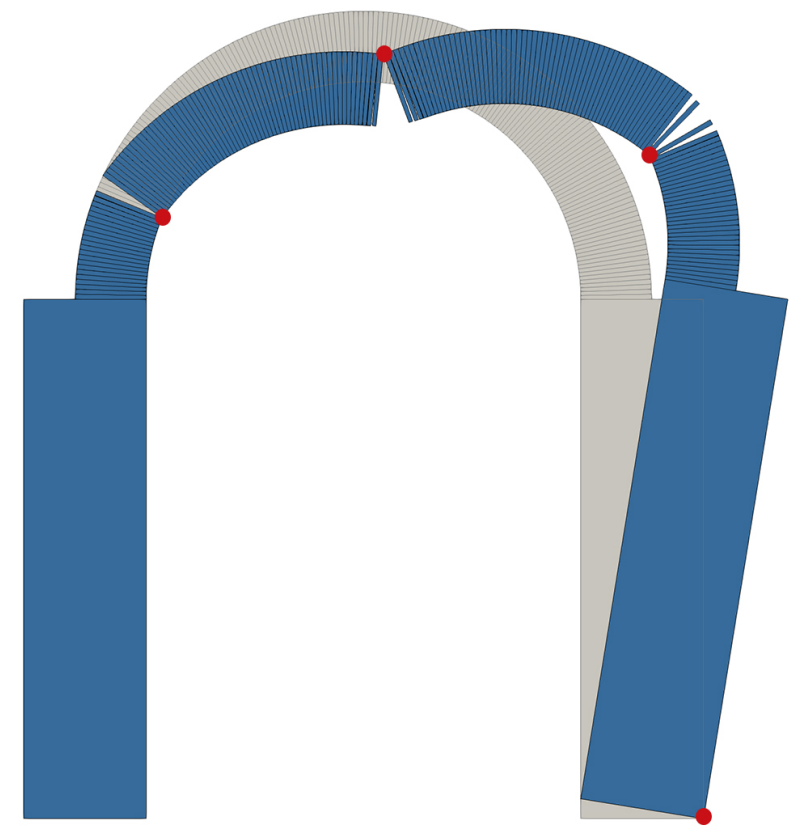

(a)

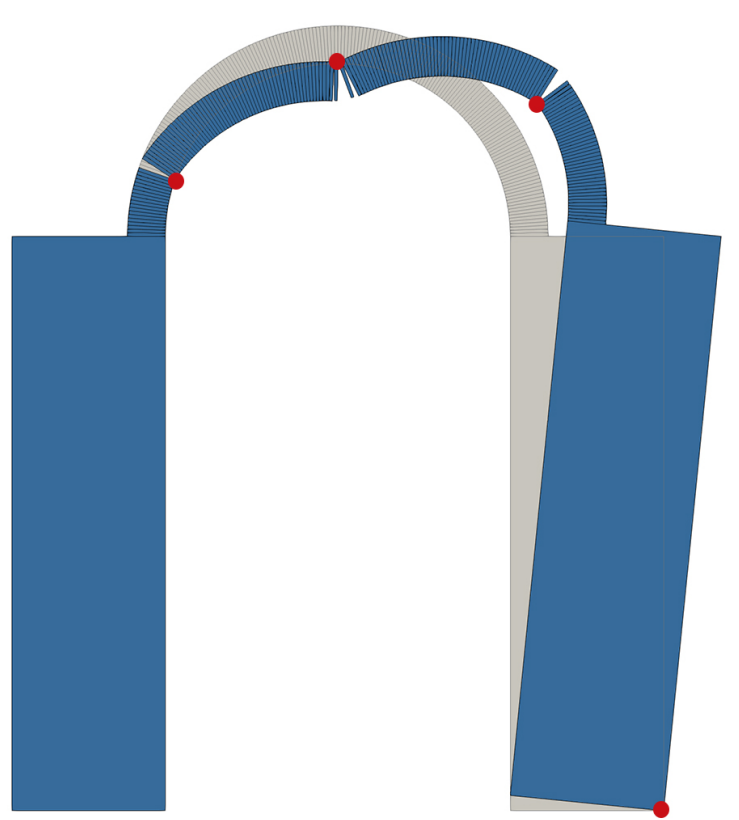

(b)

Figure 14. ALMA 2.0: the collapse mechanism obtained with the code referring to the arch studied by Calderini and Lagomarsino (2015) (a) and Dimitri and Tornabene (2015) (b)

Figures 23, 21 and 22 present a comparison of the results, in terms of collapse multipliers, related to the different geometries of pointed arches analysed: red columns refer to experimental results, grey to numerical results obtained by authors and blue ones to ALMA 2.0.

It is possible to notice how the numerical procedure developed by the authors tends to overestimate the experimental response of arches while on the contrary ALMA 2.0 provides frequently slightly lower values, except for some cases. In general, for thin arches $(S h 02)$ a little difference in terms of collapse multiplier $\alpha_{C}$ emerges; for thicker arches ( $S h 06$ - Sh1), on the contrary, a higher difference of $\alpha_{C}$ with respect to experimental values is noted.

Regarding the collapse mechanisms, authors identified the activation of two different modes: a hinging response, typical of slender specimens (more evident in circular arches where alternate hinges form) and a mechanism in which it is possible to recognize the presence of hinges as well as a sliding response (associated mostly with thick arches). Figure 24 presents some of the collapse mechanisms obtained with ALMA 2.0 compared to the corresponding experimental collapse test performed by authors. It is clear how ALMA 2.0 is able to catch the two typologies of collapse behaviour: the thin arch (a) develops several alternated plastic hinges (the difference with experimental test could be observed near the crown where two hinges forms instead of one) while the two thicker structures (b) and (c) forms plastic hinges in addition to an evident sliding of the blocks near the crown. As shown in Figures 22 and 23, in many cases the collapse multipliers obtained by ALMA 2.0 are lower than the experimental ones, even if we expected higher values, as the solution for systems with dilatant associative interfaces should be an upper bounds for the solution of systems with non-associative frictional interfaces (Palmer, 1966). This is merely related to the discrepancy between the set-up tests performed by Misseri et al. (2018) and the numerical analysis performed in ALMA 2.0. In particular, in the experimental test, sliding is not permitted at the base joints in contrast to the implementation in ALMA 2.0. The sliding collapse mechanism in ALMA 2.0 occurs for a lower value of thickness respect to the 


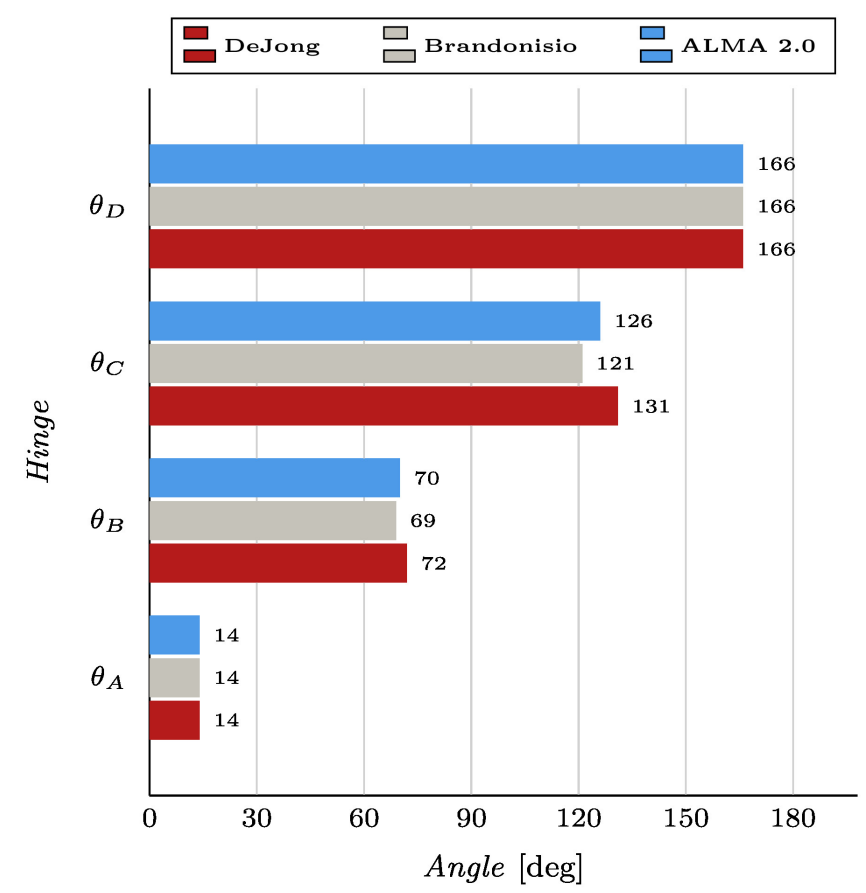

Figure 15. DeJong et al. (2008): comparison of the hinges position referring to the arch studied by various authors and with ALMA 2.0

experimental observed. The different collapse mechanisms generate the gap in terms of collapse multiplier. The reason can be found in the difference between the experimental set up and the equivalent tests implemented, such as the coefficient of friction values adopted, which for the experimental set up are different between the ground and internal joints. However, the collapse multipliers obtained by ALMA 2.0 are in many cases quite close to the experimental ones and in good agreement in percentage error respect to the numerical obtained by Misseri et al. (2018).

\section{Conclusions}

This work regards an application of ALMA 2.0, a code based on a Limit Analysis approach deriving from the pioneering works of Baggio and Trovalusci (1998, 2000), for the in-plane analysis of arches of different geometries, demonstrating its efficiency in representing the ultimate collapse behaviour of such structures. In particular the adopted model applies the upper bound theorem of Limit Analysis to a system of rigid blocks interacting through notension and associative frictional joints. The presence of friction is taken into account with a definition of a yielding surface including a sliding following the dilatancy angle. This aspect resulted particularly significant for the correct interpretation of the collapse behaviour of thicker arches. The linear programming optimization problem corresponds to the minimization of an objective function, representing the collapse multiplier, subjected to a series of

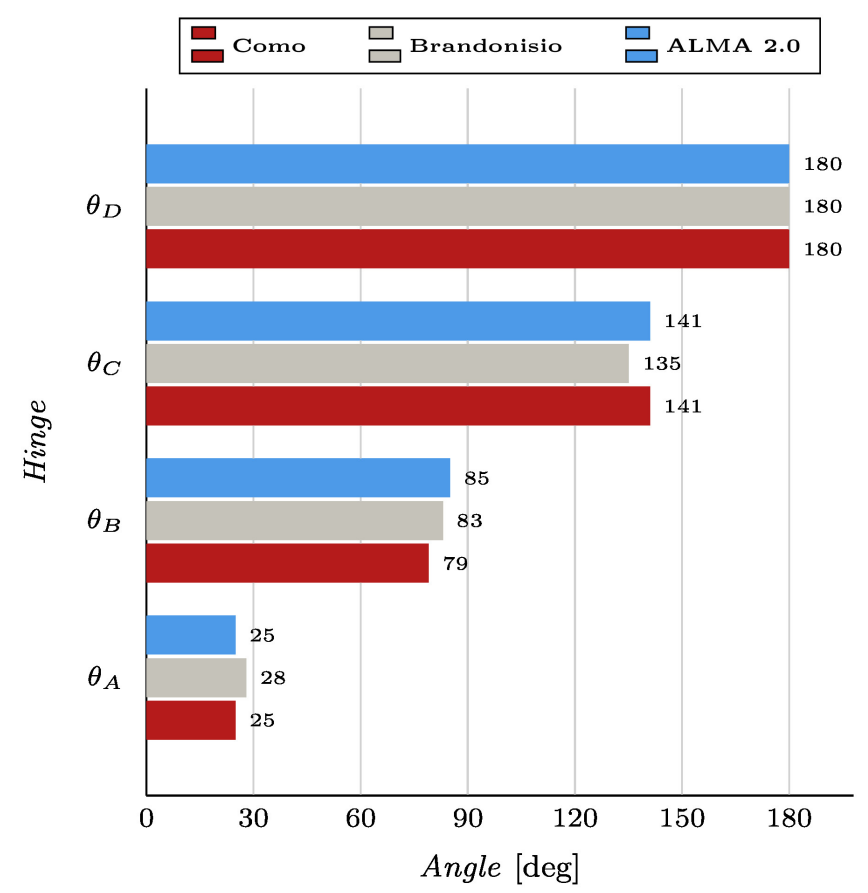

Figure 16. Como (2015): comparison of the hinges position referring to the arch studied by various authors and with ALMA 2.0

equality constraints related to the kinematic compatibility and the positiveness work of the live loads. The code has been validated against several literature benchmark contributions providing results which could be considered strongly similar to those obtained by the different authors. The response of the circular arch experimented by Cancelliere et al. (2010), subjected to monotonic vertical load applied on the extrados surface nearness the key section, has been very well caught by the Limit Analysis code with a hinging kinematism and a collapse multiplier perfectly comparable with experimental and numerical results performed by authors. Brandonisio et al. (2017) proposed a Limit Analysis approach combined with a non-linear programming technique to evaluate the seismic capacity of masonry circular arches supported on buttresses in terms of position of the plastic hinges and collapse multiplier, validating their numerical procedure with several literature contributes. In order to compare the numerical response of ALMA 2.0 with these analysis it has been considered numerically appropriate, especially for detecting the exact position of plastic hinges, to discretise the structures into rigid blocks arranged every degree with respect to the centre of the arch. Also in this case results were encouraging, being the collapse mechanisms and the collapse multipliers perfectly in agreement with those obtained by the authors. The strategy of positioning the blocks each degree proved to be successful as very precise information 


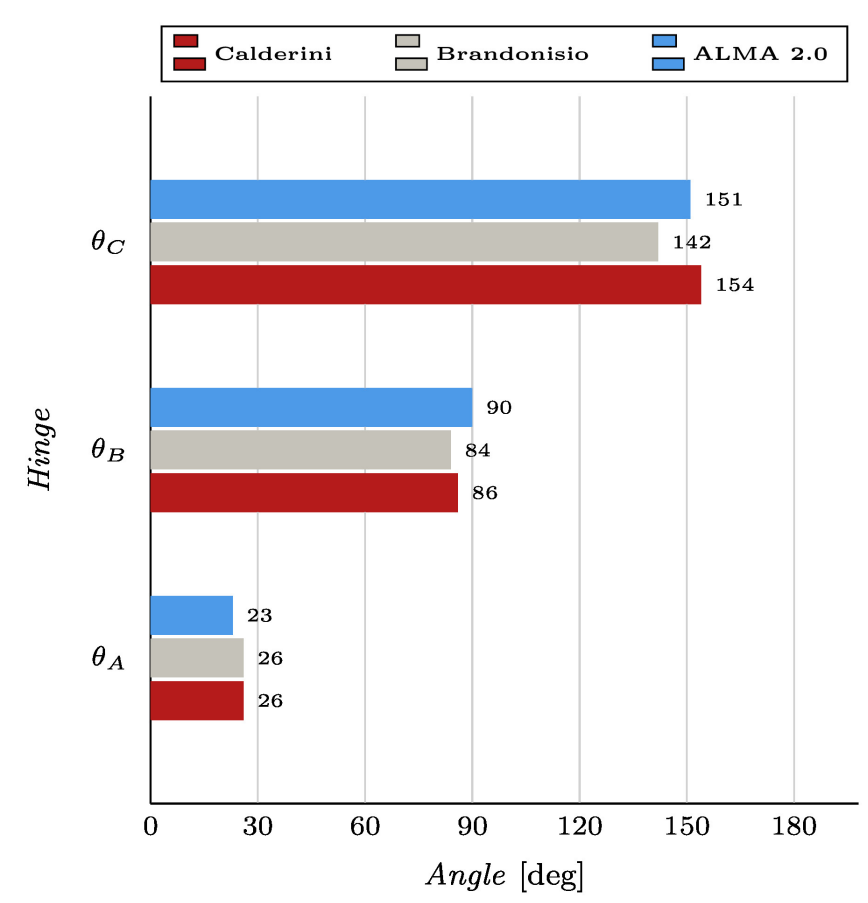

Figure 17. Calderini and Lagomarsino (2015): comparison of the hinges position referring to the arch studied by various authors and with ALMA 2.0

was obtained regarding the position of the plastic hinges. Finally, a very significant result has been obtained reproducing the arches studied by Misseri et al. (2018). Authors focused their attention on the behaviour of pointed arches subjected to a horizontal live action, reproduced using a tilting machine, on 11 scaled dry-block arches of different shapes. Authors, thanks to experimental evidences, highlighted that for sharp and thick profiles the collapse mechanism is driven by sliding, while for thinner arch the collapse is driven by a hinging mechanism. This behaviour is perfectly cought by ALMA 2.0. These results also pointed out how sliding could occur in arch structure as well as in masonry panels and façades already studied by several authors (i.e. (Ferris and Tin-Loi, 2001)). Authors, as future developments, are considering the possibility of testing different arch geometries to provide further experimental results regarding this aspect.

However some differences in the values of the collapse multipliers, compared to the experimental tests, have been observed with an overestimated capacity for the model provided by authors and an underestimated capacity for the Limit Analysis approach.

The paper highlights the importance to consider in the collapse analysis the occurrence of mechanisms of sliding at the interfaces, besides mutual rotations, that are related to a finite resistance

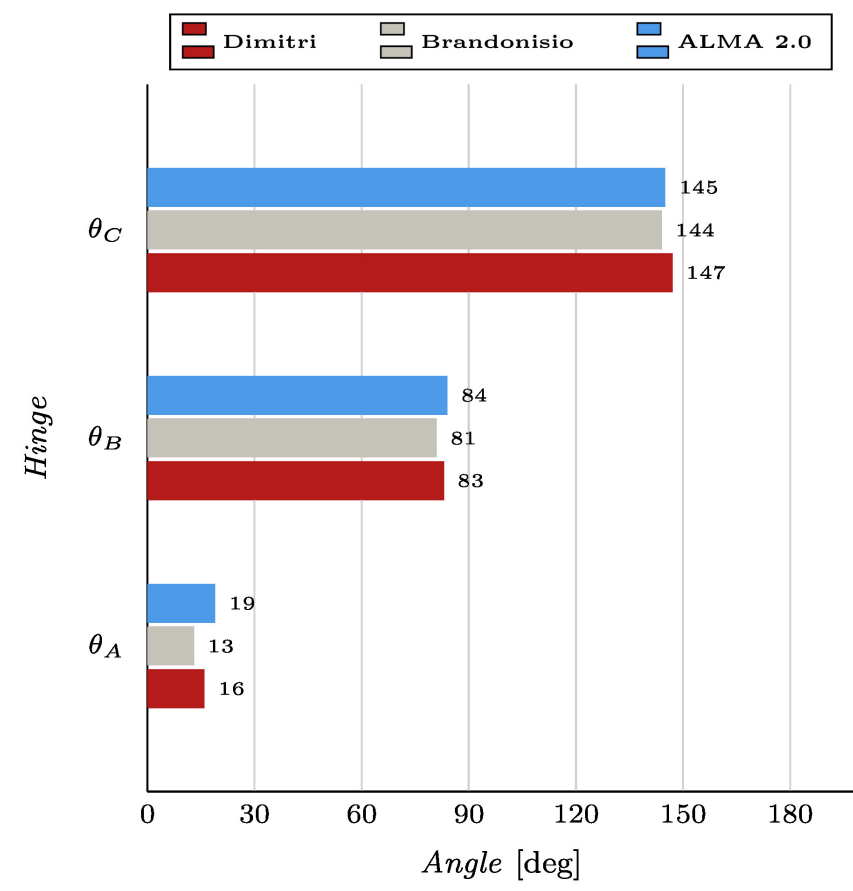

Figure 18. Dimitri and Tornabene (2015): comparison of the hinges position referring to the arch studied by various authors and with ALMA 2.0

to friction. The numerical analyses performed, in comparison to experimental results of literature, highlight that sliding or rotation mechanisms depend on the geometry of the structure. A further investigation, in conjunction with an experimental campaign, to analyse the influence of the thickness in the collapse mechanisms of arches will be object of further study.

This makes it possible to extend the study of masonry structures beyond the classic Heyman's hypotheses which, while being a powerful and relevant investigative tool, limit the range of collapse modes to hinge modes only. The developed code has proven to be numerical robust, computationally efficient and not affected by uncertainties in the definition of the calculation parameters, as friction, the only constitutive coefficient, and the geometry of the structure are the fundamental input data of the analysis. Moreover, the main advantage of using mathematical programming techniques lies in the possibility of widely exploring the solution space, thus avoiding to formulate a priori hypotheses on the mechanisms of collapse of the analysed structure. Further investigation may concern the analysis of non-regularly shaped arches and the extension of the code to three-dimensional geometries that allow the study of out-of-plane mechanisms. 


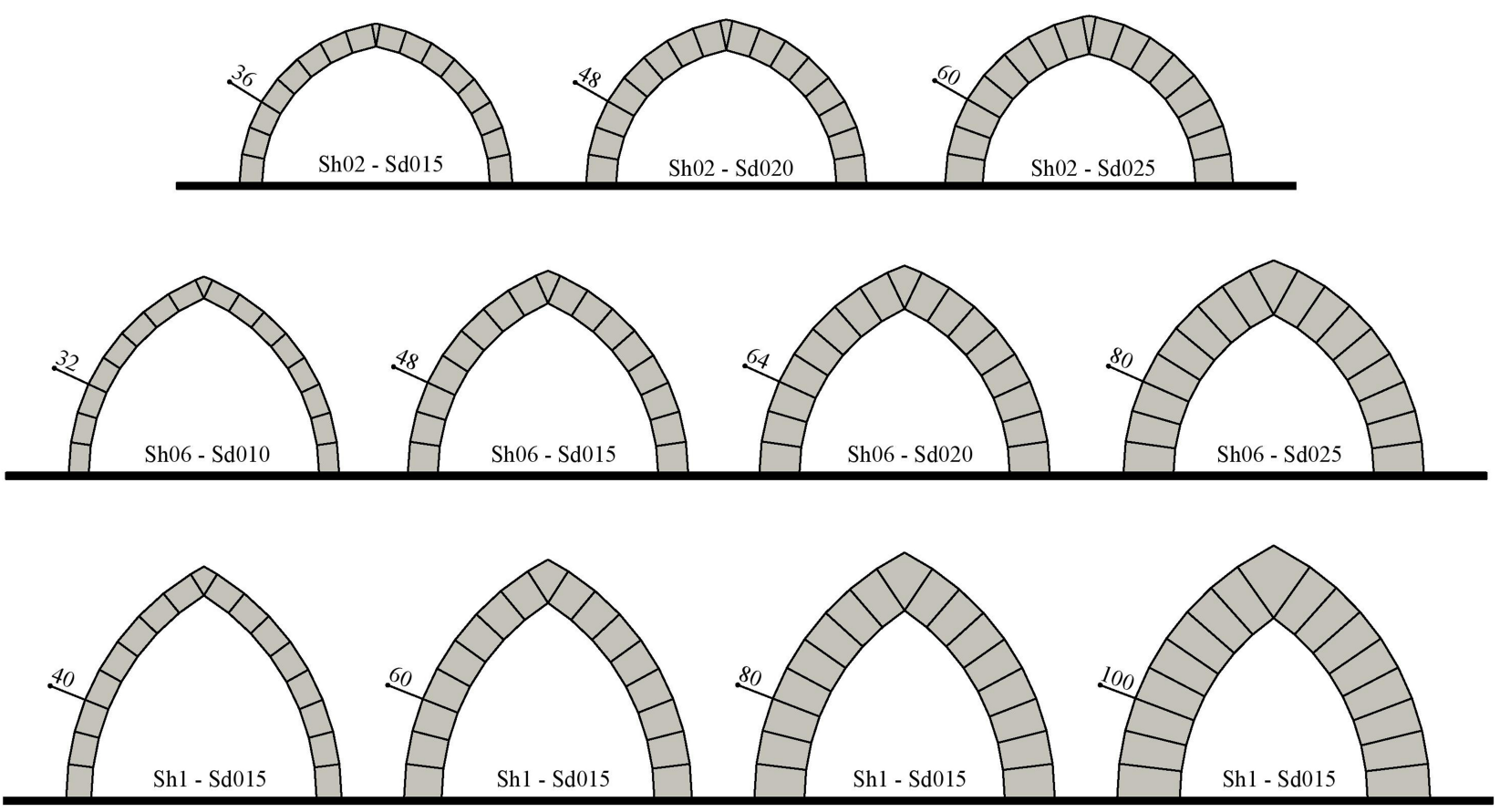

Figure 19. Different geometries, considered by Misseri et al. (2018), of pointed arches classified for Sharpness (Sh) and Slenderness $(S d)$.

\section{Acknowledgements}

This work is supported by Italian Ministry of University and Research (PRIN 2017 (B88D19001130001)and Sapienza Research Grants "Progetti Medi” 2017 (B83C17001440005); "Progetti Grandi” 2018 (B81G19000060005).

\section{REFERENCES}

Addessi D, De Bellis M and Sacco E (2016) A micromechanical approach for the cosserat modeling of composites. Meccanica 51(3): 569-592, 10 . 1007 /s11012-015-0224-y.

Addessi D, Sacco E and Di Re P (2018) Multi-scale analysis of masonry structures. pp. 307-323,

https: //www. scopus.com/inward/record.uri? eid=2-s2.0-85062311965 \&partner ID $=40$ \&md5 = 4b6e827c8c37ac1f9ab12f77f60106ba.

Aita D, Barsotti R and Bennati S (2020) Arch-piers systems subjected to vertical loads: a comprehensive review of rotational, sliding and mixed collapse modes. Archive of Applied Mechanics 10.1007/s00419-020-01766-4.

Alfano $G$ and Sacco E (2006) Combining interface damage and friction in a cohesive-zone model. International Journal for Numerical Methods in Engineering 68(5): 542-582,

$10.1002 / \mathrm{nme} .1728$.
Baggio C and Trovalusci P (1993) Discrete models for jointed block masonry walls. The Sixth North American Masonry Conference 2: 939-949.

Baggio C and Trovalusci P (1998) Limit analysis for no-tension and frictional three-dimensional discrete systems. Mechanics of Structures and Machines 26(3): 287-304, $10.1080 / 08905459708945496$.

Baggio C and Trovalusci P (2000) Collapse behaviour of three-dimensional brick-block systems using non-linear programming. Structural Engineering and Mechanics 10(2): 181-195, 10.12989/sem.2000.10.2.181.

Baraldi D, Boscato G, De Carvalho Bello C, Cecchi A and Reccia E (2019) Discrete and finite element models for the analysis of unreinforced and partially reinforced masonry arches. Key Engineering Materials 817 KEM: 229-235, 10.4028/www.scientific.net/KEM.817.229.

Barsotti R, Aita D and Bennati S (2017) Analysis of rotational and sliding collapse modes of masonry arches via durand-claye's method. 10.1063/1.5011482.

Benvenuto E (1991) An Introduction to the History of Structural Mechanics Part II: Vaulted Structures and Elastic Systems. Springer-Verlag New York, 
Limit Analysis approach for the in-plane collapse of masonry arches with hinging and sliding mechanisms

Pepe, Pingaro and Trovalusci

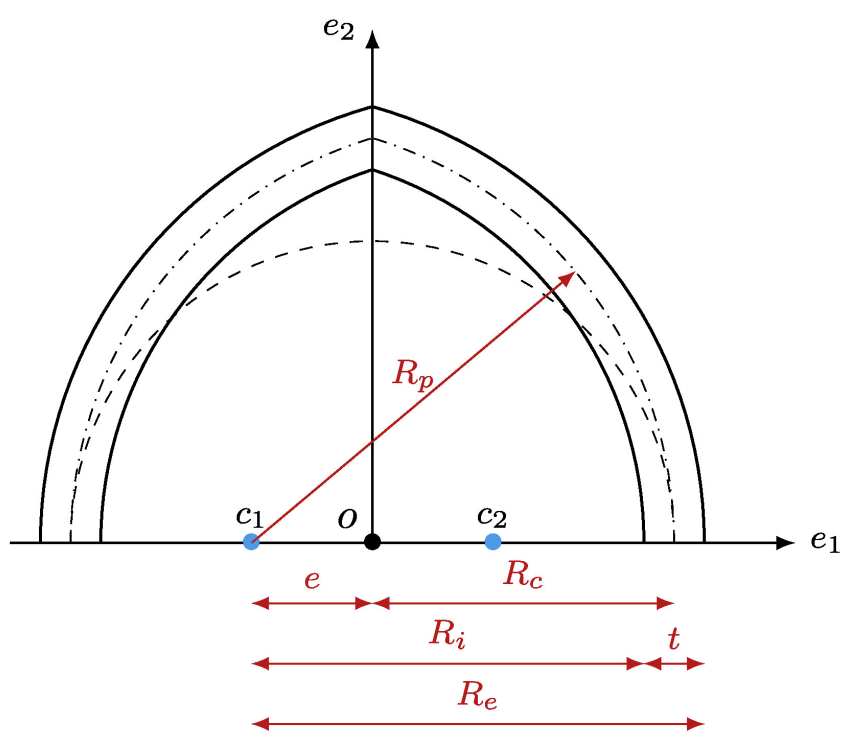

Figure 20. Schematic representation of the Misseri et al. (2018) arch

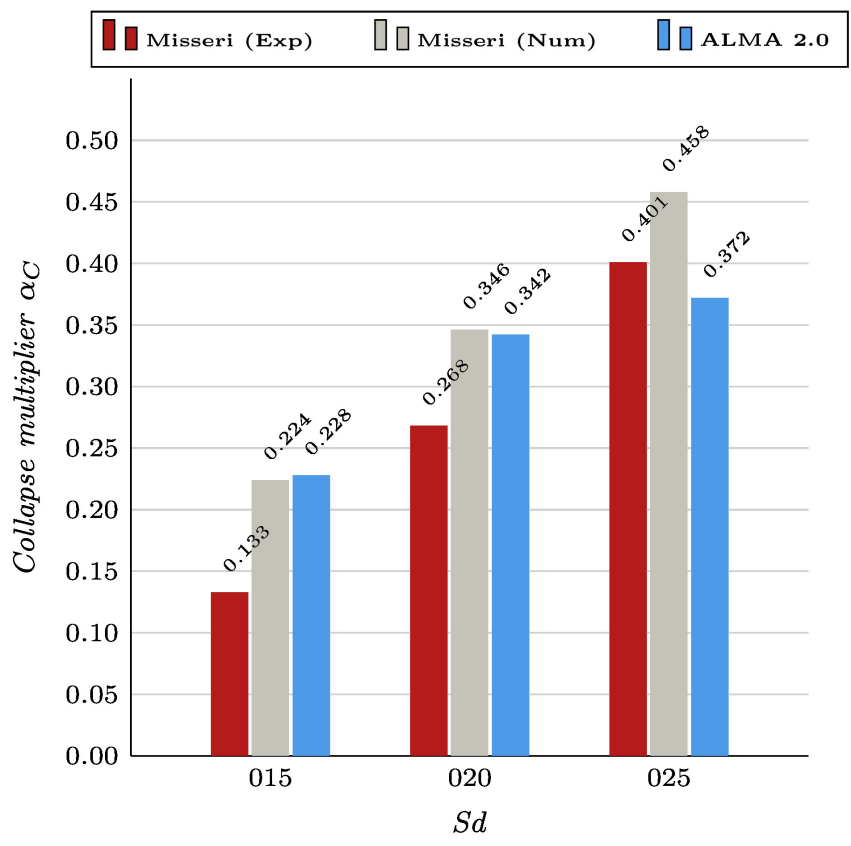

Figure 21. Misseri et al. (2018) arch of Sharpness Sh02: comparison of the collapse multipliers $\alpha_{C}$

$10.1007 / 978-1-4612-2994-0$.

Boothby T (1994) Stability of masonry piers and arches including sliding. Journal of Engineering Mechanics 120(2): 304-319,

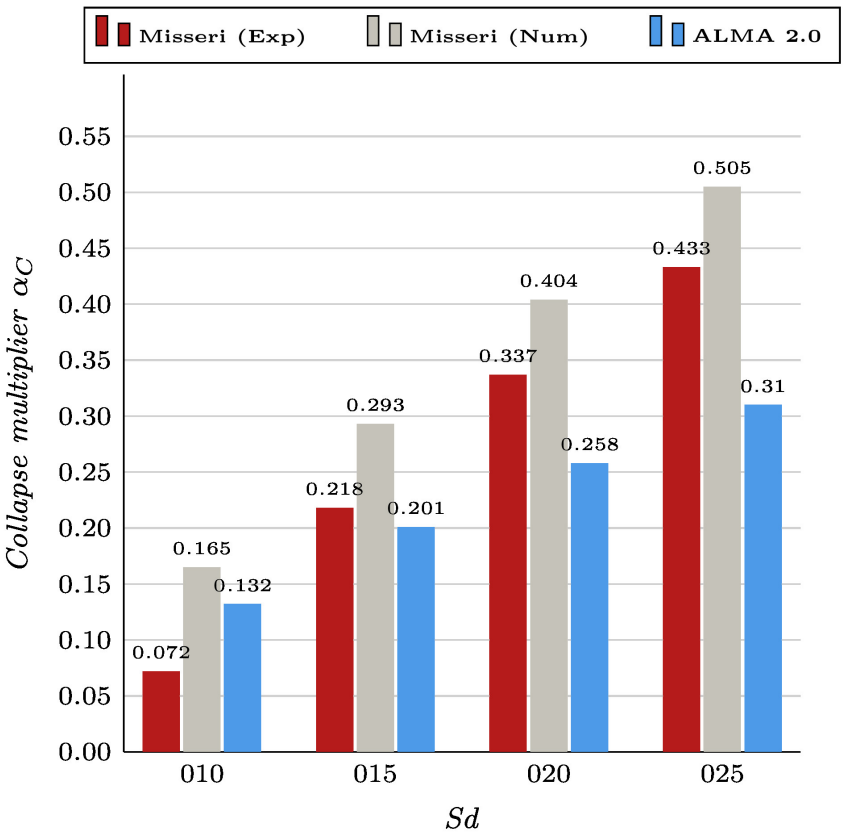

Figure 22. Misseri et al. (2018) arch of Sharpness Sh06: comparison of the collapse multipliers $\alpha_{C}$

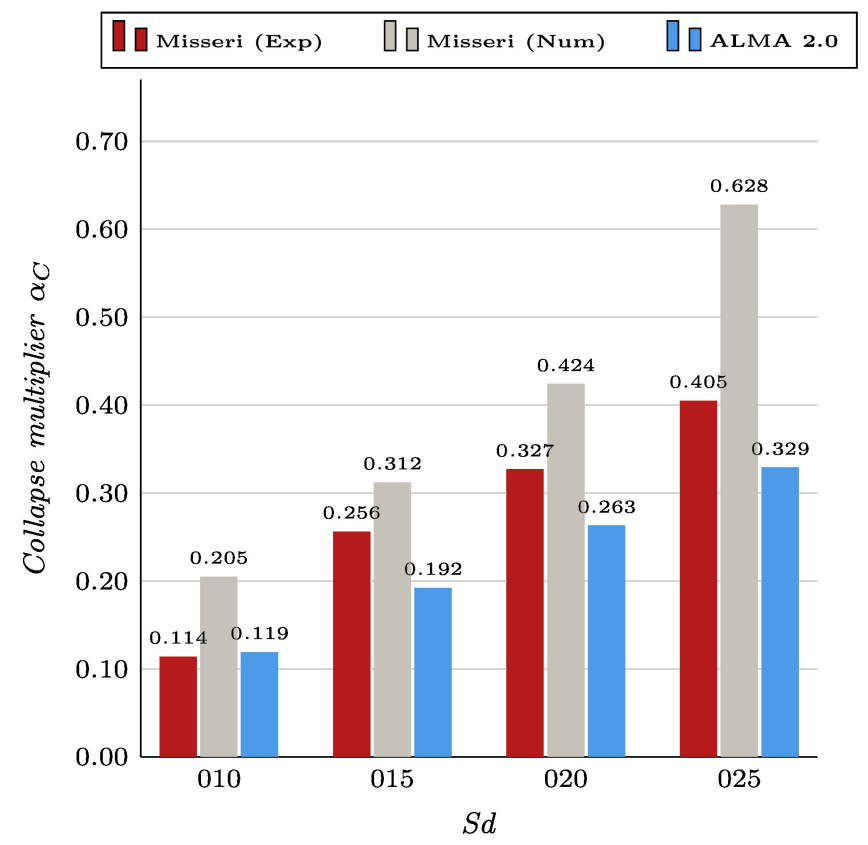

Figure 23. Misseri et al. (2018) arch of Sharpness $S h 1$ : comparison of the collapse multipliers $\alpha_{C}$ 


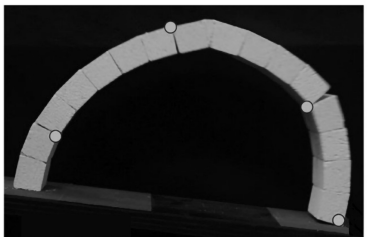

(a)

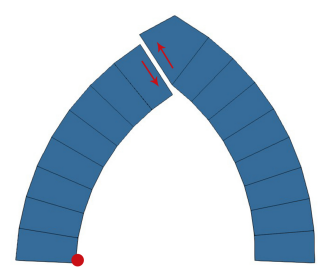

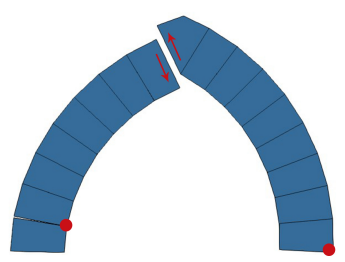
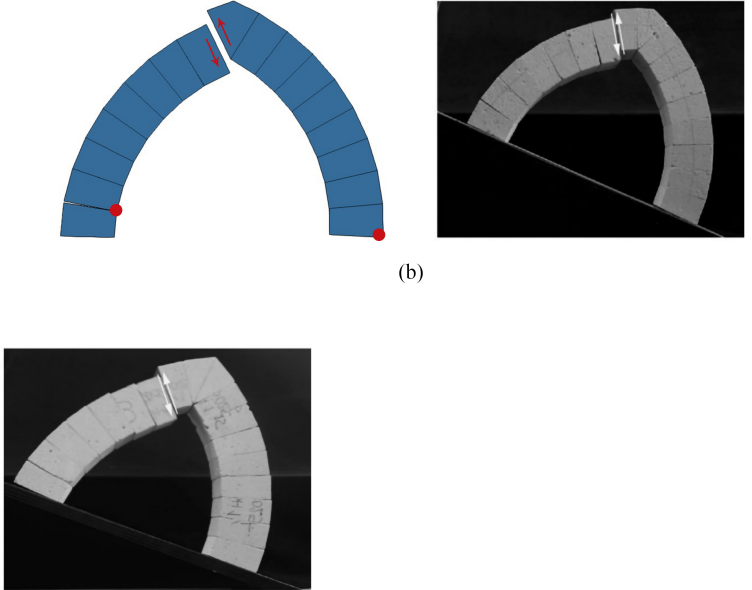

(c)

Figure 24. Misseri et al. (2018): exemplifying comparison of hinging and sliding collapse mechanisms obtained using ALMA 2.0 and their corresponding experimental test referring to (a) arch $S h 2-S d 015$, (b) $S h 06-S d 025$, (c) $S h 1-S d 025$

10.1061/(ASCE) 0733-9399(1994)120:2(304).

Brandonisio G, Mele E and De Luca A (2017) Limit analysis of masonry circular buttressed arches under horizontal loads.

Meccanica 52(11-12): 2547-2565,

$10.1007 / \mathrm{s} 11012-016-0609-6$.

Bruggi M (2020) A constrained force density method for the funicular analysis and design of arches, domes and vaults. International Journal of Solids and Structures 193-194: 251-269, 10.1016/j.ijsolstr.2020.02.030.

Calderini C and Lagomarsino S (2015) Seismic response of masonry arches reinforced by tie-rods: Static tests on a scale model. Journal of Structural Engineering (United States) 141(5), $10.1061 /$ (ASCE) ST.1943-541X.0001079.

Cancelliere I, Imbimbo M and Sacco E (2010) Experimental tests and numerical modeling of reinforced masonry arches.

Engineering Structures 32(3): 776-792,

$10.1016 / j$.engstruct.2009.12.005.

Capecchi D, Ruta G and Trovalusci P (2011) Voigt and Poincaré's mechanistic-energetic approaches to linear elasticity and suggestions for multiscale modelling. Archive of Applied Mechanics 81(11): 1573-1584, $10.1007 / \mathrm{s} 00419-010-0502-z$.

Casapulla C and Maione A (2020) Experimental and analytical investigation on the corner failure in masonry buildings: Interaction between rocking-sliding and horizontal flexure. International Journal of Architectural Heritage 14(2): 208-220, 10.1080/15583058.2018.1529206.

Cascini L, Gagliardo R and Portioli F (2020) LiABlock3D: A software Tool for Collapse Mechanism Analysis of Historic Masonry Structures. International Journal of Architectural
Heritage 14(1): 75-94,

$10.1080 / 15583058.2018 .1509155$.

Chiozzi $A$, Malagù $M$, Tralli $A$ and Cazzani $A$ (2016) Archnurbs:

Nurbs-based tool for the structural safety assessment of masonry arches in matlab. Journal of Computing in Civil Engineering 30(2),

$10.1061 /$ (ASCE) CP.1943-5487.0000481.

Como M (2015) Statics of Historic Masonry Constructions: An Essay. Springer International Publishing,

10.1007/978-3-319-13003-3_3.

Coulomb CA (1776) Essai sur une application des règles de maximis \& minimis à quelques problèmes de statique, relatifs à l'architecture. Paris : De l'Imprimerie Royale.

De Lorenzis L, DeJong M and Ochsendorf J (2007a) Failure of masonry arches under impulse base motion. Earthquake Engineering and Structural Dynamics 36(14): 2119-2136, 10.1002 / eqe. 719.

De Lorenzis L, Dimitri R and La Tegola A (2007b) Reduction of the lateral thrust of masonry arches and vaults with FRP composites. Construction and Building Materials 21(7): 1415-1430, $10.1016 / j$.conbuildmat.2006.07.009, cited By 66.

DeJong M, De Lorenzis L, Adams S and Ochsendorf J (2008) Rocking stability of masonry arches in seismic regions. Earthquake Spectra 24(4): 847-865, 10 . 1193/1.2985763. Del Piero G (1989) Constitutive equation and compatibility of the external loads for linear elastic masonry-like materials. Meccanica 24(3): 150-162, 10.1007 / BE 01559418.

Di Re P, Addessi D and Sacco E (2018) A multiscale force-based curved beam element for masonry arches. Computers and 
Structures 208: 17-31,

$10.1016 / j$.compstruc.2018.06.009.

Dimitri R and Tornabene F (2015) A parametric investigation of the seismic capacity for masonry arches and portals of different shapes. Engineering Failure Analysis 52: 1-34, 10.1016/j.engfailanal.2015.02.021.

Drucker DC (1953) Coulomb friction, plasticity, and limit loads. Technical report, Brown Univ Providence RI DIV of Applied Mathematics.

Eroglu U, Paolone A, Ruta G and Tüfekci E (2020) Exact closed-form static solutions for parabolic arches with concentrated damage. Archive of Applied Mechanics 90(4): 673-689, 10.1007/s00419-019-01633-x.

Fantuzzi N, Trovalusci P and Dharasura S (2019) Mechanical behavior of anisotropic composite materials as micropolar continua. Frontiers in Materials $\mathbf{6}$,

10.3389 /fmats.2019.00059.

Ferris M and Tin-Loi F (2001) Limit analysis of frictional block assemblies as a mathematical program with complementarity constraints. International Journal of Mechanical Sciences 43(1): 209-224, $10.1016 /$ S $0020-7403$ (99) 00111-3.

Gambarotta L and Lagomarsino S (1997) Damage models for the seismic response of brick masonry shear walls. part ii: The continuum model and its applications. Earthquake Engineering and Structural Dynamics 26(4): 441-462,

$10.1002 /$ (SICI) $1096-9845$ (199704) 26:4<441: : AID-EQE651>3.0.CO;2-0.

Gilbert M, Casapulla C and Ahmed H (2006) Limit analysis of masonry block structures with non-associative frictional joints using linear programming. Computers and Structures 84(13-14): 873-887,

$10.1016 / j$.compstruc. 2006.02 .005$.

Greco F, Leonetti L, Luciano R and Nevone Blasi P (2016) An adaptive multiscale strategy for the damage analysis of masonry modeled as a composite material. Composite Structures 153: 972-988, $10.1016 / j$. compstruct.2016.06.066.

Greco F, Leonetti L, Luciano R and Trovalusci P (2017) Multiscale failure analysis of periodic masonry structures with traditional and fiber-reinforced mortar joints. Composites Part B: Engineering 118: 75-95, $10.1016 / j$.compositesb.2017.03.004.

Grillanda N, Chiozzi A, Milani G and Tralli A (2019) Collapse behavior of masonry domes under seismic loads: An adaptive NURBS kinematic limit analysis approach. Engineering Structures 200, 10.1016/j. engst ruct. 2019.109517.

Heyman J (1966) The stone skeleton. International Journal of Solids and Structures 2(2):

249-256,IN1-IN4,257-264,IN5-IN12,265-279,

https: / /www. scopus. com/inward/record.uri? eid=2-s2.0-0004942133\&partnerID $=40$ \&md5= 038571 f2507293cb3e3733e941balf47.
Heyman J (1969) The safety of masonry arches. International Journal of Mechanical Sciences 11(4):

363-382,IN3-IN4,383-385,

https : / / www. scopus.com/inward/record.uri? eid=2-s2.0-0004047701\&partner $I D=40 \&$ md5 = 7f6d9aae6d0ba71ac800cc898147131c.

Heyman J (2017) The safety of masonry arches. Taylor and Francis Inc., https://www. scopus. com/inward/record. uri?eid=2-s2.0-85070954957 \&partnerID $=40$ \& md5 =f50af6582e84af448ab30c3ccc9e5a 71 .

Kirsch U (1993) Structural optimization: fundamentals and applications. Springer-Verlag Berlin Heidelberg, $10.1007 / 978-3-642-84845-2$.

Kooharian A (1952) Limit analysis of voussoir (segmental) and concrete arches. J Am Concr Inst 24(4): 317-328.

Landolfo R, Gagliardo R, Cascini L, Portioli F, Malena M, Tomaselli $G$ and de Felice $G$ (2020) Rigid block and finite element analysis of settlement-induced failure mechanisms in historic masonry walls. Frattura ed Integrita Strutturale 14(51): 517-533, 10.3221/IGF-ESIS.51.39.

Leonetti L, Fantuzzi N, Trovalusci P and Tornabene F (2019) Scale effects in orthotropic composite assemblies as micropolar continua: A comparison between weakand strong-form finite element solutions. Materials 12(5), 10.3390 /ma12050758.

Leonetti L, Greco F, Trovalusci P, Luciano R and Masiani R (2018) A multiscale damage analysis of periodic composites using a couple-stress/Cauchy multidomain model: Application to masonry structures. Composites Part B: Engineering 141: 50-59, 10.1016/j.compositesb.2017.12.025.

Livesley R (1978) Limit analysis of structures formed from rigid blocks. International Journal for Numerical Methods in Engineering 12(12): 1853-1871,

$10.1002 / \mathrm{nme} .1620121207$.

Lotfi $\mathrm{H}$ and Shing P (1994) Interface model applied to fracture of masonry structures. Journal of Structural Engineering (United States) 120(1): 63-80, $10.1061 /$ (ASCE) 0733-9445 (1994)120:1 (63).

Lourenço P and Rots J (1997) Multisurface interface model for analysis of masonry structures. Journal of Engineering Mechanics 123(7): 660-668, 10.1061/(ASCE) 0733-9399 (1997) 123:7 (660).

Masiani R and Trovalusci P (1996) Cosserat and Cauchy materials as continuum models of brick masonry. Meccanica 31(4): 421-432, 10.1007/BF0 0429930.

Milani G (2011) Simple lower bound limit analysis homogenization model for in- and out-of-plane loaded masonry walls. Construction and Building Materials 25(12): 4426-4443, $10.1016 / j$.conbuildmat.2011.01.012.

Milani G and Taliercio A (2016) Limit analysis of transversally loaded masonry walls using an innovative macroscopic strength criterion. International Journal of Solids and Structures $\mathbf{8 1}$ : 274-293, 10.1016/j.ijsolstr.2015.12.004. 
Misseri G, DeJong M and Rovero L (2018) Experimental and numerical investigation of the collapse of pointed masonry arches under quasi-static horizontal loading. Engineering Structures 173: 180-190,

$10.1016 / j$.engstruct .2018 .06 .009 .

Mousavian E and Casapulla C (2020) The role of different sliding resistances in limit analysis of hemispherical masonry domes.

Frattura ed Integrita Strutturale 14(51): 336-355,

10.3221 / IGF-ESIS.51.25.

Oliveira D and Lourenço P (2004) Implementation and validation of a constitutive model for the cyclic behaviour of interface elements. Computers and Structures 82(17-19): 1451-1461, $10.1016 / j$.compstruc.2004.03.041.

Oppenheim I (1992) The masonry arch as a four-link mechanism under base motion. Earthquake Engineering \& Structural Dynamics 21(11): 1005-1017, 10.1002 /eqe. 4290211105.

Palmer AC (1966) A limit theorem for materials with non-associated flow laws. Journal of Mécanique 5(2): 217-222.

Peña F, Prieto F, Lourenço P, Campos Costa A and Lemos J (2007) On the dynamics of rocking motion of single rigid-block structures. Earthquake Engineering and Structural Dynamics 36(15): 2383-2399, 10 . 1002 / eqe. 739.

Pepe M (2020) Numerical modeling for masonry: ALMA 2.0, A computational code for the limit analysis of historical masonry structures. PhD thesis, Sapienza University of Rome.

Pepe M, Pingaro M, Reccia E and Trovalusci P (2019) Micromodels for the in-plane failure analysis of masonry walls with friction: Limit analysis and dem-fem/dem approaches. In AIMETA 2019 XXIV conference. The Italian Association of Theoretical and Applied Mechanics, Rome, Italy.

Pepe M, Pingaro M, Trovalusci P, Reccia E and Leonetti L (2020a) Micromodels for the in-plane failure analysis of masonry walls: Limit analysis, FEM and FEM/DEM approaches. Frattura ed Integrita Strutturale 14(51): 504-516, 10.3221/IGF-ESIS.51.38.

Pepe M, Sangirardi M, Reccia E, Pingaro M, Trovalusci P and de Felice G (2020b) Failure analysis of masonry structures subjected to settlements. Frontiers in Building In Press.

Portioli F, Casapulla C, Gilbert M and Cascini L (2014) Limit analysis of $3 \mathrm{~d}$ masonry block structures with non-associative frictional joints using cone programming. Computers and Structures 143: 108-121, 10.1016/j.compstruc.2014.07.010.

Radenkovic D (1961) Théorèmes limites pour un matériau de Coulomb á dilation non standardisée. Comptes rendus hebdomadaires des séances de l'Académie des Sciences 252(26): 4103.

Reccia E, Cecchi A and Tralli A (2013) Homogenization of masonry vault bridges: Sensitivity to external stone arch. Civil-Comp Proceedings 102,

https://www.scopus.com/inward/record.uri?
eid=2-s2.0-84893904529\&partnerID $=40$ \&md5= bce3bb8a055417b90d34f92dd484a0d3.

Reccia E, Leonetti L, Trovalusci P and Cecchi A (2018) A multiscale/multidomain model for the failure analysis of masonry walls: A validation with a combined FEM/DEM approach. International Journal for Multiscale Computational Engineering 16(4): 325-343,

10.1615 / Int JMultCompEng. 2018026988.

Roca P, Molins C and Marí A (2005) Strength capacity of masonry wall structures by the equivalent frame method. Journal of Structural Engineering 131(10): 1601-1610, 10.1061/(ASCE) 0733-9445 (2005)131:10 (1601).

Rossi M, Calderini C, Di Napoli B, Cascini L and Portioli F (2020) Structural analysis of masonry vaulted staircases through rigid block limit analysis. Structures 23: 180-190, 10.1016/j.istruc.2019.10.015.

Trovalusci P (2014) Molecular Approaches for Multifield Continua: origins and current developments. CISM International Centre for Mechanical Sciences, Courses and Lectures 556: 211-278, 10.1007/978-3-7091-1812-2_7.

Trovalusci P and Masiani R (2003) Non-linear micropolar and classical continua for anisotropic discontinous materials. International Journal of Solids and Structures 40(5): 1281-1297, $10.1016 /$ S $0020-7683$ (02) $00584-X$.

Trovalusci P and Pau A (2014) Derivation of microstructured continua from lattice systems via principle of virtual works: The case of masonry-like materials as micropolar, second gradient and classical continua. Acta Mechanica 225(1): 157-177, 10.1007/s00707-013-0936-9.

Trovalusci P, Varano V and Rega G (2010) A generalized continuum formulation for composite microcracked materials and wave propagation in a bar. Journal of Applied Mechanics, Transactions ASME 77(6), 10.1115/1.4001639. 